\title{
Relationship Between Polymorphism in Exon 8 of Estrogen Receptor Alpha Gene and Osteoporosis in Saudi Women
}

\author{
Lina M Al Neghery ${ }^{1 *}$, Maha H Daghestani ${ }^{1 *}$, Suphia M Sherbeeni ${ }^{2}$, Sana A Ajaj ${ }^{3}$, Mazen H Daghestani ${ }^{4}$, \\ Abdelmoneim Eldali ${ }^{5}$ and Arjumand Warsy ${ }^{6}$
}

${ }^{1}$ Department of Zoology, College of Science, King Saud University, Riyadh, Saudi Arabia

${ }^{2}$ Department of Diabetes and Endocrinology, King Fahad Medical City, Diabetes Center, Riyadh, Saudi Arabia

${ }^{3}$ Primary Care Clinics in King Khalid University Hospital, Riyadh, Saudi Arabia

${ }^{4}$ Department of Obstetrics \& Gynecology, Umm-Al-Qura University, Makkah, Saudi Arabia

${ }^{5}$ Department of Biostatistics and Scientific Computing, King Faisal Specialist Hospital \& Research Centre, Riyadh, Saudi Arabia

${ }^{6}$ Central Laboratory of College of Science, King Saud University, Riyadh, Saudi Arabia

*Corresponding author: Lina M Al Neghery and Maha H Daghestani, Department of Zoology, College of Science, King Saud University, Riyadh, Saudi Arabia, Tel: +966565656781; E-mail: lina-al-neghery@hotmail.com

Received date: January 17, 2018; Accepted date: January 29, 2018; Published date: February 07, 2018

Copyright: (c) 2018 Al Neghery LM, et al. This is an open-access article distributed under the terms of the Creative Commons Attribution License, which permits unrestricted use, distribution, and reproduction in any medium, provided the original author and source are credited.

Citation: Al Neghery LM, Daghestani MH, Sherbeeni SM, Ajaj SA, Daghestani MH, et al. (2018) Relationship Between Polymorphism in Exon 8 of Estrogen Receptor Alpha Gene and Osteoporosis in Saudi Women. Eur Exp Biol Vol. 8 No. 1:3.

\section{Abstract}

Objectives: Alternations in the estrogen receptor alpha gene $(E R \alpha)$ play an essential role in osteoporosis etiology. In this study, the relationship between a single nucleotide polymorphism (SNP) in ER (G2014A) and osteoporosis in Saudi women were investigated.

Methods: In this research 40 females with osteoporosis and 41 healthy controls ranging in age from 35 to 75 years were examined. Demographic data were recorded, and blood samples were drawn in plain and in EDTA tubes for estimation of estrogens in the serum and extraction of DNA, respectively. The DNA was used to amplify the fragment of interest carrying the SNP in ER $\alpha$ by polymerase chain reaction (PCR). The PCR product was subjected to DNA sequencing.

Results: G2014A was polymorphic in Saudi women. Genotypes and allele frequencies were compared in the osteoporotic and non-osteoporotic groups. Although the genotypes of osteoporotic and non-osteoporotic subjects were significantly different $(p=0.0157)$, the allelic frequency was not significantly different $(p=0.519)$. Estrogen levels significantly differed between osteoporotic and nonosteoporotic subjects (mean \pm SD E2: $46.6 \pm 30.7$ vs. $68.7 \pm$ $47.1 \mathrm{pg} / \mathrm{mL}, \mathrm{p}=0.0143$ ). Importantly, a significant difference in waist-hip ratio in osteoporotic patient and the nonosteoporotic group was detected $(0.8 \pm 0.1$ vs. $0.9 \pm 0.0$, $\mathrm{p}=0.0174)$.

Conclusion: Although there was no relationship between G2014A and osteoporosis in Saudi women, this study sheds light on another aspect, such as the significant difference in estrogen levels in these two groups. Furthermore, an advantageous effect of fat on bone mass was observed in the non-osteoporotic group.

Keywords: Osteoporosis; Bone mineral density; Estrogen receptor- $\alpha$ gene; Single-nucleotide polymorphism; Estrogen; Genetics

\section{Introduction}

Osteoporosis is a public health problem and affects the human skeleton as defined in Bone Health and Osteoporosis [1]. Low bone density, deterioration of bone tissue, and interruption of bone architecture are prominent features in osteoporosis patients. Consequently, bones tend to be weak and become more susceptible to fracture. The standard deviation of bone mineral density (BMD) is a customary measurement in osteoporosis diagnosis. According to the diagnostic classification of the World Health Organization (WHO), osteoporosis exists when a BMD of the hip or lumbar spine is less than or equal to 2.5 standard deviations below the mean BMD of an adolescent reference population. The risk of fracture is higher in those with the lowest BMD according to the WHO definition. However, these disorders affect an enormous number of people of both sexes and all races, and the prevalence is increasing as the population ages [2]. Women are the most likely to develop osteoporosis than men.

Several hormones play an important role in bone density regulation and distribution. Sex hormones are required for skeletal progress and establishing peak bone mass, and estrogen is involved in bone maintenance [3-5]. These effects involve controlling the maturation of growth plates, which tightly close during longitudinal growth; regulating bone metabolism, 
particularly, cortical and cancellous; supporting reaching a peak bone mass, and inhibiting bone loss. These roles are required for the regulation of skeletal homeostasis for women [6-8]. The effects of estrogen on bone are mediated by its binding to specific estrogen receptors (ERs) located in the cytosol and nucleus. These receptors belong to the nuclear receptor hormone superfamily and are ligand-inducible transcription factors.

ERs mediate different mechanical response processes and function at different cellular levels; for instance, osteoblasts, osteoclasts, bone marrow stromal cells, and estrogen receptor alpha $(E R \alpha)$ affect cortical bone. In this regard, $E R \alpha$ in osteoblast progenitors is required for mechanosensing at the periosteum, but not in trabecular bone, indicating that osteoblast progenitors residing in different compartments respond to different cues such as growth factors and hormones. Previous studies in mice showed that apoptosis of osteocytes induced by estrogen deficiency is not uniform, but rather restricted to distinct anatomical areas of the cortical bone [9]. It seems to be the major receptor controlling estrogen effects on the bone and has an essential effect on bone turnover regulation and reducing the loss of bone mass $[5,10,11]$. Thus, osteoporosis appears to be a polygenic condition with multiple genes potentially playing minor roles [12]. The human ER $\alpha$ gene (also known as ESR1) is located on chromosome $6 \mathrm{q} 25$ and spans more than 140 kilobases $[13,14]$.

In the Saudi population, studies have revealed that $30-50 \%$ of Saudi women above 40 years of age develop osteoporosis [15] We hypothesized that single-nucleotide polymorphisms (SNPs) in ER $\alpha$ might affect the prevalence of osteoporosis in Saudi females. One such polymorphism is G2014A (SNP ID number: rs2228480), and studies have suggested that the $G$ to $A$ transition (G2014A) in exon 8 of the $E R \alpha$, which changes the corresponding codon from ACG to ACA, has functional significance in affected women. Although the identified SNP does not alter the amino acid sequence, this SNP is located six nucleotides upstream of the stop codon TGA [16]. Moreover, genetic diversity is a major concern considering the necessity of preserving what may be a precious and irreplaceable richness, regarding new productive demands [17]. Conservation should be based on a deep knowledge of the genetic resources of the specific breed [18]. Therefore, it is important to characterize important genes using molecular tools. The maintenance of genetic diversity requires the adequate implementation of conservation priorities and sustainable management programs, which should be based on comprehensive information regarding the structure of the populations, including sources of genetic variability among and within breeds. Genetic diversity is an essential component for population survival, evolution, genetic improvement and adaptation to changing environmental conditions [19]. Moreover, genes affecting polygenic traits and characterizing them are difficult to identify $[20,21]$. The applications of molecular genetics have many important advantages [22], and determination of gene polymorphism is important [23-25], hence the goal of this study was to determine the relationship between this polymorphism and osteoporosis in Saudi women.
Osteoporosis and obesity are public health diseases involving several genetic and environmental factors. The precursor stem cell adipocytes and osteoblast differentiation involve the same pathways, and the hormones secreted from adipocytes affect the development of bone mass. Thus, assessing this relationship is important for understanding these disorders [26].

\section{Materials and Methods}

\section{Subjects}

The study population was comprised of Saudi women ranging in age from 35 to 75 years. The group included 40 osteoporotic women, and 41 healthy women were enrolled as controls. All women were non-smokers, non-alcoholic, and did not use estrogen replacement medicine. Furthermore, the study population groups divided into two subgroups of the postmenopausal women (aged above 50 years); the Nonosteoporotic postmenopausal women $(n=16)$, and Osteoporotic postmenopausal women $(n=22)$.

All volunteers in this study subjected to dual energy X-ray absorptiometry (DXA) which was the tool for assessment the BMD status and they donated blood samples after consent forms were obtained from the Department of Endocrinology and Diabetes in King Fahad Medical City in Riyadh (IRB\#10-026).

\section{Anthropometric measurements}

For each member of the study group, anthropometric measurements were conducted using standardized techniques. These included measurements of height and weight, which were used to calculate body mass index $\left(\mathrm{BMI}, \mathrm{kg} / \mathrm{m}^{2}\right)$ in addition to the waist and hip circumference to calculate the waist - hip ratio (WHR).

\section{Bone mineral density measurement}

BMD was measured by dual-energy X-ray absorptiometry using standardized and quality-assured equipment. BMD at the lumbar spine and right femoral neck were measured for each subject. The WHO has standardized the interpretation of BMD results based on a comparison of a patient's BMD with the mean for a normal young adult population of the same sex and race [27]. Patient's BMD values were calculated as a T-score, which is the number of standard deviations above or below the mean BMD for normal young adults as follows:

- Normal BMD: T-score no more than -1 SD below the young adult mean.

- Osteopenia: T-score between -1.0 and, -2.5.

- Osteoporosis: T-score equal to or less than -2.5.

- Severe osteoporosis: T-score below -2.5 for patients with a fragility fracture.

\section{Measurement of residual estradiol concentrations}

A plain red-top tube or serum separator tube was used to calculate circulating residual estradiol (E2) levels assayed using BioSource Enzyme Amplified Sensitivity Immunoassay E2-EASIA 
(Thermo Fisher Scientific, Waltham, MA, USA), which is a competitive binding immunoassay for quantitative determination of estradiol in the serum and plasma. The capacity of KAP0621 is 96 tests (BioSource Europe S.A. Cat. No. 103305/A).

\section{G2014A genotyping}

Genomic DNA was extracted in EDTA tubes from peripheral blood leucocytes using the commercially available Gentra Systems Kit (Minneapolis, MN, cat \#158389, USA). The concentration and purity of the DNA were estimated before analysis.

The DNA segment representing G2014A of the ESR1 was amplified by polymerase chain reaction (PCR) using a forward primer (5'-TTTACCCTCATCATGCACCA-3') and reverse primer ( $5^{\prime}$ CTATGACCTGCTGCTGGAGA- $3^{\prime}$ ). The method employs one forward and reverse of primer to amplify the DNA fragment containing the SNP, these primers were designed using the primer design computer program (http://primer3.ut.ee/). The primers were designed by limiting the fragment sizes to the range of $200-400 \mathrm{bp}$.

The PCR conditions were standardized to generate a product containing the SNP of interest. The amplification consisted of the following steps: initial denaturation at $95^{\circ} \mathrm{C}$ for $15 \mathrm{~min}$, followed by 34 cycles of denaturation at $95^{\circ} \mathrm{C}$ for $4 \mathrm{~min}$, annealing at $60^{\circ} \mathrm{C}$ for $1 \mathrm{~min}$, extension at $72^{\circ} \mathrm{C}$ for $1 \mathrm{~min}$, and final extension for 10 $\min$ at $72^{\circ} \mathrm{C}$. The resulting DNA fragments were separated on an agarose gel (Figure 1). Nucleotide sequencing showed in Figure 2 was carried out using the ABI Big Dye Terminator protocol on an ABI 3100 Avant Genetic Analyzer (Thermo Fisher Scientific, USA).

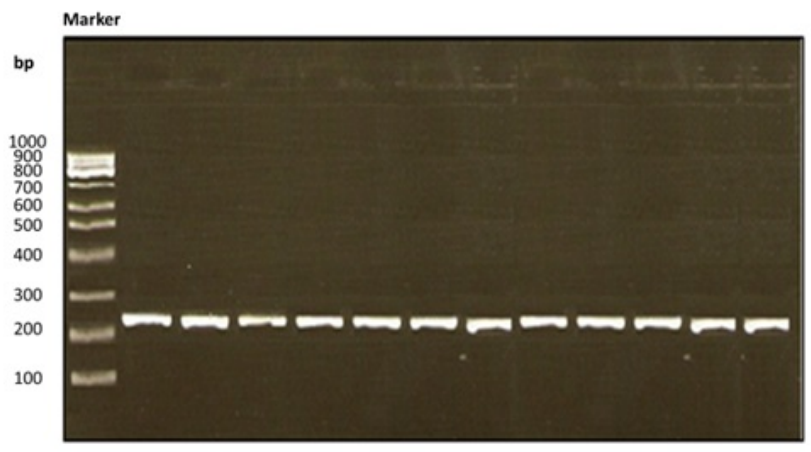

Figure 1. Agarose gel electrophoresis for the amplified fragments of DNA.

\section{Statistical analysis}

Using SPSS version 20, mean, standard deviation, standard error of the mean was calculated for each parameter in the different groups [28]. Continuous variables between groups were compared by independent t-tests or analyses of covariance as appropriate. Categorical variables were compared by the chisquare test.
(A)

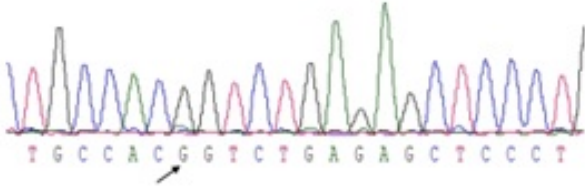

(B)

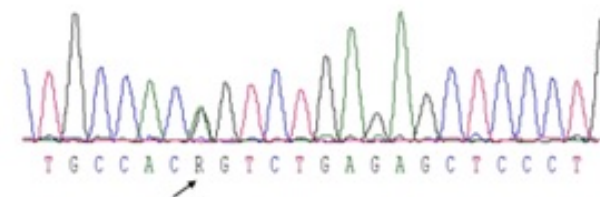

(C)

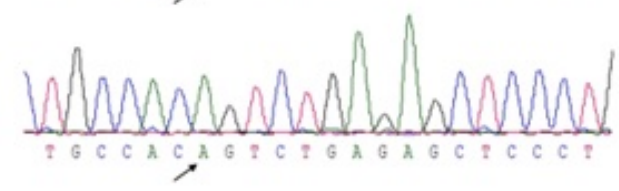

Figure 2. The chromatogram of sanger sequenced data showing (A) the wild-type, (B) heterozygous, and (C) homozygous alleles in exon 8 of ESR1 gene. Arrows indicate the position of the polymorphic nucleotide.

Correlation studies were conducted, and Pearson Correlation Coefficient ( $r$ ) was obtained [29]. Statistical, computational software was available at Institute fur Humangenetik (URL: https://ihg.gsf.de/cgi-bin/hw/hwa1.pl) was used to calculate the odds ratio (OR), 95\% confidence intervals $(\mathrm{Cl})$, Chi-square $\left(\chi^{2}\right)$ and $p$-value for each genotype and allele to compare the significance of the difference between the patients and controls [16]. Analysis of variance was used to identify mean differences for some variables according to genetic sequences and allele classification. The differences were considered significant at $p \leq$ 0.05 .

\section{Results}

Anthropometric, biochemical, and hormonal parameters were obtained for each group as showed in Table 1 . The results were compared using the t-test, and the clinical and biochemical characteristics of osteoporotic patients vs. non-osteoporotic subjects were compared. We found a significant difference between WHR in osteoporotic patients and non-osteoporotic subjects (mean \pm SD WHR: $0.8 \pm 0.1$ vs. $0.9 \pm 0.0, p=0.0174$ ). There was also a significant difference in circulating E2 level, where the osteoporotic patients had a lower circulating E2 than non-osteoporotic subjects (mean \pm SD E2: $46.6 \pm 30.7$ vs. $68.7 \pm$ $47.1 \mathrm{pg} / \mathrm{mL}, \mathrm{p}=0.0143$ ). While there was no significant difference at the level of estrogen hormone among postmenopausal women in the osteoporotic patient group and non-osteoporotic subjects as shown in Table 2 . We tested the correlation coefficients between estrogen and age in osteoporotic patients and found a weakly decreasing linear relationship ( $r=-0.34409, p=0.0297$ ). We tested the correlation between estrogen and $\mathrm{BMI}$, which also showed a weak downhill linear relationship $(r=-0.21832, p=0.1759)$. Similarly, for nonosteoporotic subjects, we tested the correlation coefficients between estrogen and age and found a moderately decreasing linear relationship $(r=-0.42791, p=0.0053)$. On the other hand, 
the correlation between estrogen and BMI showed a nonsignificantly increasing linear relationship $(r=0.21789, p=0.1711)$, as shown in Table 3.

Table 1. Clinical and biochemical characteristics of osteoporotic patients and controls.

\begin{tabular}{|c|c|c|c|}
\hline$p$ value & $\begin{array}{l}\text { Non- } \\
\text { osteoporotic } \\
(n=41) \text { (Mean } \pm \\
\text { SD) }\end{array}$ & $\begin{array}{l}\text { Osteoporotic } \\
(n=40) \text { (Mean } \pm \\
\text { SD) }\end{array}$ & Variable \\
\hline$<0.0001$ & $-0.1 \pm 0.7$ & $-2.7 \pm 1.1$ & T-Score $(\mathrm{L})$ \\
\hline$<0.0001$ & $0.5 \pm 0.9$ & $-1.6 \pm 1.1$ & T-Score (RF) \\
\hline 0.4559 & $48.1 \pm 9.8$ & $50.1 \pm 13.9$ & Age (yr) \\
\hline 0.6636 & $31.7 \pm 6.0$ & $32.3 \pm 7.7$ & BMI $\left(\mathrm{kg} / \mathrm{m}^{2}\right)$ \\
\hline 0.0143 & $68.7 \pm 47.1$ & $46.6 \pm 30.7$ & E2 Level $(\mathrm{pg} / \mathrm{mL})$ \\
\hline 0.0174 & $0.9 \pm 0.0$ & $0.8 \pm 0.1$ & WHR \\
\hline
\end{tabular}

$\mathrm{SD}=$ Standard Deviation, Signification value $=\mathrm{p} \leq 0.05, \mathrm{~L}=$ Lumbar, RF=Right Femur, yr=year, BMI=Body Mass Index, E2=17 $\beta$-estradiol, WHR=waist- hip ratio

Table 2. Clinical and biochemical characteristics of postmenopausal women with osteoporosis and without.

\begin{tabular}{|l|l|l|c|}
\hline Variable & $\begin{array}{l}\text { Osteoporotic } \\
\text { postmenopausal } \\
\text { women (n=22) } \\
\text { (Mean } \pm \text { SD) }\end{array}$ & $\begin{array}{l}\text { Non-osteoporotic } \\
\text { postmenopausal } \\
\text { women (n=16) } \\
\text { (Mean } \pm \text { SD) }\end{array}$ & p value \\
\hline T-Score (L) & $-3.0 \pm 0.7$ & $0.2 \pm 0.8$ & $<0.0001$ \\
\hline T-Score (RF) & $-1.5 \pm 1.3$ & $0.5 \pm 0.9$ & $<0.0001$ \\
\hline Age (yr) & $61.1 \pm 7.6$ & $58.5 \pm 5.9$ & 0.2639 \\
\hline BMI (kg/m²) & $32.9 \pm 7.5$ & $29.6 \pm 4.5$ & 0.1182 \\
\hline $\begin{array}{l}\text { E2 Level } \\
\text { (pg/mL) }\end{array}$ & $38.3 \pm 27.1$ & $48.5 \pm 20.0$ & 0.1891 \\
\hline \multicolumn{2}{|l|}{$\begin{array}{l}\text { L=Lumbar, RF=Right Femur, yr=year, BMI=Body Mass Index, E2=17ß-estradiol, } \\
\text { pictograms per milliliter, SD=Standard Deviation, Signification value=p } \leq 0.05\end{array}$} \\
\hline
\end{tabular}

Table 3. Correlation coefficients between estrogen levels with age and BMI in osteoporotic patients and non-osteoporotic group.

\begin{tabular}{|c|c|c|c|c|c|c|c|}
\hline \multicolumn{4}{|c|}{$\begin{array}{l}\text { Pearson Correlation Coefficients for Osteoporotic group, } n=40 \\
\text { Probability }>|r| \text { under H0: Rho }=0\end{array}$} & \multicolumn{4}{|c|}{$\begin{array}{l}\text { Pearson Correlation Coefficients for Osteoporotic group, } n=40 \\
\text { Probability }>|r| \text { under H0: Rho }=0\end{array}$} \\
\hline & & Age (yr) & BMI $\left(\mathrm{kg} / \mathrm{m}^{2}\right)$ & & & Age (yr) & BMI $\left(\mathrm{kg} / \mathrm{m}^{2}\right)$ \\
\hline \multirow{2}{*}{ E2 Level (pg/ml) } & $r$ & -0.34409 & -0.21832 & \multirow{2}{*}{ E2 Level (pg/ml) } & $r$ & -0.42791 & 0.21789 \\
\hline & $\mathrm{P}$ & 0.0297 & 0.1759 & & $\mathrm{p}$ & 0.0053 & 0.1711 \\
\hline
\end{tabular}

Table 4 shows the allele and genotype distributions of G2014A, which obeyed Hardy-Weinberg equilibrium. Among osteoporotic patients, no females were homozygous for the ' $A$ ' allele, while seven were heterozygous. The ' $A$ ' allele frequency in the patient group was 5 . In non-osteoporotic subjects, 2 cases were homozygous for the ' $A$ ' allele, 1 case was heterozygous, and the ' $A$ ' allele frequency in this group was 7 . The genotype distribution in this study in subjects with and without osteoporosis was significantly different $(p=0.0157)$, but no significant difference found in allele frequency between these two groups $(p=0.519)$.

Table 4. Alleles and genotype distributions based on G2014A SNP in osteoporotic patients and non-osteoporotic subjects.

\begin{tabular}{|c|c|c|c|c|c|c|c|}
\hline SNP & Variation & Osteoporotic group & $\begin{array}{l}\text { Non-osteoporotic } \\
\text { group }\end{array}$ & OR & $\mathrm{Cl}$ & $x^{2}$ & $p$ value \\
\hline \multirow{6}{*}{$\begin{array}{c}\text { rs2228 } \\
480\end{array}$} & GG & $33(0.825)$ & $38(0.93)$ & \multicolumn{3}{|l|}{ Ref } & 0.0157 \\
\hline & GA & $7(0.175)$ & $1(0.02)$ & 25 & $0.75-81$ & 5.83 & \\
\hline & AA & 0 & $2(0.05)$ & 4 & 0 & 0 & \\
\hline & $\mathrm{GA}+\mathrm{AA}$ & $7(0.086)$ & $3(0.037)$ & 2.687 & $0.64-11.2$ & 1.94 & 0.166 \\
\hline & G & $77(0.94)$ & $73(0.91)$ & 0.677 & $0.449-4.86$ & & \\
\hline & $A$ & $5(0.06)$ & $7(0.09)$ & 1.477 & $0.206-2.229$ & 0.42 & 0.519 \\
\hline
\end{tabular}

The study population was divided into three groups based on the genotypes of G2014A and the value of the anthropometric parameters, BMD and hormone levels were separately calculated. The results in the different genotypes were compared using Students ' $t$ ' test. The results are presented in
Table 5. A significant relationship was observed between the AA genotype and lumbar T-score $(p=0.032)$.

Table 5. Relationship between rs2228480 genotypes and study variables for our subjects. 


\begin{tabular}{|c|c|c|c|c|}
\hline $\begin{array}{l}\text { Variable } \\
\text { s }\end{array}$ & $\begin{array}{l}\text { Genoty } \\
\text { pe }\end{array}$ & $\begin{array}{l}\text { Numb } \\
\text { er }\end{array}$ & $\begin{array}{lr}\text { Mean } & \pm \\
\text { Standard. } & \text { Error } \\
\text { Difference } & \end{array}$ & $p$ value \\
\hline \multirow[t]{3}{*}{$\begin{array}{l}\text { T-score } \\
\text { (L) }\end{array}$} & GG & 71 & $-1.266 \pm 0.1899$ & GG vs. AA 0.532 \\
\hline & GA & 8 & $-2.388 \pm 0.3388$ & GG vs. GA 0.057 \\
\hline & AA & 2 & $-0.550 \pm 0.0500$ & GA vs. AA 0.032 \\
\hline \multirow{3}{*}{$\begin{array}{l}\text { T-score } \\
\text { (RF) }\end{array}$} & GG & 71 & $-.532 \pm 0.1773$ & GG vs. AA 0.588 \\
\hline & GA & 8 & $-1.125 \pm 0.4003$ & GG vs. GA 0.281 \\
\hline & AA & 2 & $0.050 \pm 0.9500$ & $G A$ vs. $A A=0.236$ \\
\hline \multirow{3}{*}{ Age (yr) } & GG & 71 & $50.42 \pm 1.374$ & GG vs. AA 0.066 \\
\hline & GA & 8 & $39.50 \pm 3.012$ & GG vs. GA 0.012 \\
\hline & $A A$ & 2 & $35.00 \pm 2.000$ & GA vs. AA 0.499 \\
\hline \multirow{3}{*}{$\begin{array}{l}\text { BMI } \\
\left(\mathrm{kg} / \mathrm{m}^{2}\right)\end{array}$} & GG & 71 & $31.62 \pm 0.812$ & GG vs. AA 0.526 \\
\hline & GA & 8 & $34.00 \pm 2.646$ & GG vs. GA 0.358 \\
\hline & AA & 2 & $28.50 \pm 4.500$ & GA vs. AA 0.372 \\
\hline \multirow{3}{*}{ WHR } & GG & 71 & $0.865 \pm 0.0106$ & GG vs. AA 0.583 \\
\hline & GA & 8 & $0.888 \pm 0.0125$ & GG vs. GA 0.481 \\
\hline & AA & 2 & $0.900 \pm 0.0000$ & GA vs. AA 0.645 \\
\hline \multirow{3}{*}{$\begin{array}{l}\text { E2 level } \\
(\mathrm{pg} / \mathrm{ml})\end{array}$} & GG & 71 & $58.35 \pm 4.945$ & GG vs. AA 0.251 \\
\hline & GA & 8 & $46.88 \pm 7.097$ & GG vs. GA 0.446 \\
\hline & AA & 2 & $93.50 \pm 53.500$ & GA vs. AA 0.109 \\
\hline
\end{tabular}

$\mathrm{L}=$ Lumbar, RF=Right Femur, yr=year, BMI=Body Mass Index, E2=17ß-estradiol pictograms per milliliter

\section{Discussion}

Genetic factors play critical roles in the pathogenesis of osteoporosis. The purpose of this study was to investigate the relationship between G2104A and osteoporosis in Saudi females. Previous studies of twins and families suggested that $50-85 \%$ of the variance in peak bone mass is genetically determined, based on different skeletal regions and the age of the subjects [12,29-31]. Since $E R \alpha$ is a major functional candidate gene for bone density regulation, we investigated polymorphism in this gene in relation to osteoporosis.

The genotype distributions in this study were significantly different between osteoporotic patients and non-osteoporotic subjects ( $p=0.0157)$, and the G2014A allele was independently associated with osteoporosis. Although, the allele frequency did not differ between the two groups. Thus, a partial relationship exists between the G2014A SNP and osteoporosis in Saudi women as determined based on the genotype distribution of the study subjects. In contrast, a study in Thailand found an association between a G2014A and the severity of osteoporosis in 106 osteoporotic postmenopausal women and 122 nonosteoporotic postmenopausal women, as the A allele was overrepresented in subjects with osteoporosis $(p<0.05)$. However, it remains unknown whether these findings were related to differences in bone mass from childhood or because of postmenopausal bone loss. Thus, additional studies are needed to confirm this association [16].

This G2014A SNP has been implicated in osteoporosis development in Mexican women in a study of 70 osteoporotic and 70 non-osteoporotic women. The frequencies of the ' $G$ ' allele and GG genotype were considerably higher in osteoporotic than in non-osteoporotic Mexican women, suggesting an association between the ' $G$ ' allele and osteoporosis. Women homozygous for the ' $G$ ' allele displayed the lower lumbar BMD and T-score values than women with the GA and AA genotypes. However, additional molecular studies are required to clarify this point [32-34]. While we found no significant differences between the frequencies of the ' $A$ ' and ' $G$ ' alleles in the different groups and osteoporosis in this study, the genotype frequencies showed some differences. Multiple factors may influence the polymorphism association, such as differences in age, menopausal status, inadequate sample size, ethnicity, and mixed populations.

A large number of studies have attempted to evaluate the association between ER $\alpha$ alleles and BMD [35] and some studies found an association between ER $\alpha$ alleles and ultrasound properties of bones [36]. We found an association between the G2014A genotype and BMD, and AA which was significantly associated with the lumbar T-score $(p=0.032)$, which may agree with the results of previous studies.

Finally, our study provides insight into the differences between our population frequencies and frequencies in other populations. Most frequently observed allele and genotype frequency differences between populations have likely resulted from diversity in sample sizes and ethnicities or environmental backgrounds. These studies demonstrate the importance of investigating SNPs, which can impact the risk of diseases such as osteoporosis.

Furthermore, several lines of evidence have revealed a correlation between estrogen, which is part of the endocrine system that regulates BMD, and the occurrence of osteoporosis. Estrogen deficiency implicates menopause development, which leads to increased bone resorption and eventual acceleration of osteoporosis [37-39]. However, clinical trials showed that estrogen supplementation markedly delays osteoporosis development [40]. Laboratory experiments in animals revealed a significant decrease in bone mass after ovariectomy [41]. Some studies showed that the likelihood of osteoporosis in men was related to a failure in altering testosterone to estrogen ratio because of aromatase deficiency [42]. However, men with osteoporosis and open epiphyses are responsive to estrogen but not testosterone therapy [43]. These studies support the importance of estrogen and demonstrate that its receptor, which is localized in both the cytosol and nucleus of bone cells, protects against osteoporosis [44].

A significant difference in the level of estrogen hormone $(p=0.0143)$ among osteoporotic and non-osteoporotic women aged between 35 and 75 years was found in this study. However, we found no significant difference in estrogen hormone among postmenopausal women in the osteoporosis patient group and non-osteoporotic group. A study in Thailand study found no 
significant difference in circulating estrogen among postmenopausal women [15]. This discrepancy occurred because estrogen hormone regressed in postmenopausal women until the levels of estrogen became convergent in the same age group.

Indeed, according to epidemiological studies, the correlation between BMI and bone mass remains unclear, while another group of studies found that higher BMI was correlated with high bone mass. Furthermore, adipocytes are important sources of estrogen in women for inhibiting bone resorption [45-47]. Thus, we found a correlation between estrogen and $\mathrm{BMI}$ in the nonosteoporotic group, although the correlation was weak $(r=0.21789)$; these results support that estrogen levels are involved in the complex relationship between BMI and osteoporosis. We also evaluated an additional aspect of fat mass and osteoporosis and found a significant difference between our subjects and WHR, in which fat likely benefits bone $(p=0.0174)$. In contrast, another study evaluated 4489 Caucasian and 1988 healthy unrelated Chinese premenopausal women aged 19.6-45.1 years and 19.1-90.1, respectively. Their study used dual-energy X-ray absorptiometry scanners to assess osteoporosis and percentage fat mass, which is the ratio of the fat mass divided by total body weight to determine the obesity of subjects. The study showed that an increased fat mass might not have a beneficial effect on bone mass $[48,49]$. Although their study analyzed the effect of mechanical loading on bone mass, differences in measurement and analysis methods may explain the different results.

In conclusion, although we found no association between the G2014A SNP of the ER $\alpha$ and osteoporosis in Saudi women, genetic heterogeneity was present and showed inconsistent results with previous studies. Overall, this study sheds light on another aspect, such as the significant difference in estrogen levels in these two groups. Furthermore, an advantageous effect of fat on bone mass was observed in the non-osteoporotic group.

\section{Acknowledgements}

We are grateful to the patients and control subjects for their participation in our study. We would like to also thank Research Center of the Female Scientific and Medical Colleges at King Saud University for supporting the study.

\section{References}

1. No authors (2004) Bone Health and Osteoporosis: A Report of the Surgeon General. U.S. Department of Health and Human Services. Rockville MD, Office of the Surgeon General.

2. Wright NC, Looker AC, Saag KG, Curtis JR, Delzell ES, et al. (2014) The recent prevalence of osteoporosis and low bone mass in the United States based on bone mineral density at the femoral neck or lumbar spine. J Bone Miner Res 29: 2520-2526.

3. Turner RT, Riggs BL, Spelsberg TC (1994) Skeletal effects of estrogen. Endocr Rev 15: 275-300.

4. Prince RL (1994) Counterpoint: estrogen effects on calcitropic hormones and calcium homeostasis. Endrocr Rev 15: 301-309.
5. Compston JE (2001) Sex steroids and bone. Physiol Rev 81: 441-447.

6. Khosla S, Melton LJ 3rd, Atkinson EJ, O'Fallon WM (2001) Relationship of serum sex steroid levels to longitudinal changes in bone density in young versus elderly men. J Clin Endocrinol Metab 86: 3555-3561.

7. Khosla S, Melton LJ 3rd, Riggs BL (2002) Clinical review 144: Estrogen and the male skeleton. J Clin Endocrinol Metab 87: 1443-1450.

8. Gennari L, Merlotti D, Martini G, Gonnelli S, Franci B, et al. (2003) Longitudinal association between sex hormone levels, bone loss, and bone turnover in elderly men. J Clin Endocrinol Metab 88: 5327-5333.

9. Emerton KB, Hu B, Woo AA, Sinofsky A, Hernandez C, et al. (2010) Osteocyte apoptosis and control of bone resorption following ovariectomy in mice. Bone 46: 577-583.

10. Bland R (2000) Steroid hormone receptor expression and action in bone. Clin Sci (Lond) 98: 217-240.

11. Bord S, Horner A, Beavan S, Compston J (2001) Estrogen receptors alpha and beta are differentially expressed in developing human bone. J Endocrinol Metab 86: 2309-2314.

12. Gueguen R, Jouanny P, Guillemin F, Kuntz C, Pourel J, et al. (1995) Segregation analysis and variance components analysis of bone mineral density in healthy families. J Bone Miner Res 10: 2017-2022.

13. Green S, Walter P, Kumar V, Krust A, Bornert JM, et al. (1986) Human oestrogen receptor cDNA: sequence, expression and homology to v-erb-A. Nature 320: 134-139.

14. Greene GL, Gilna P, Waterfield M, Baker A, Hort Y, et al. (1986) Sequence and expression of human estrogen receptor complementary DNA. Science 231: 1150-1154.

15. Oommen AAI (2014) Prevalence of osteoporosis and factors associated with osteoporosis in women above 40 years in the Northern Part of Saudi Arabia. J Res Med Sci 2: 2740-2748.

16. Ongphiphadhanakul B, Chanprasertyothin S, Payattikul P, Saetung S, Piaseu N, et al. (2001) Association of a G2014A transition in exon 8 of the estrogen receptor-alpha gene with postmenopausal osteoporosis. Osteoporos Int 12: 1015-1019.

17. Khodabakhshzadeh R, Mohammadabadi MR, Esmailizadeh A Shahrebabak HM, Bordbar F, et al. (2016) Identification of point mutations in exon 2 of GDF9 gene in Kermani sheep. Pol J Vet Sci 19: 281-289.

18. Zamani P, Akhondi M, Mohammadabadi MR (2015) Associations of Inter-Simple Sequence Repeat loci with predicted breeding values of body weight in sheep. Small Rumin Res 132: 123-127.

19. Ebrahimi MTV, Mohammadabadi MR, Esmailizadeh A (2017) Using microsatellite markers to analyze genetic diversity in 14 sheep types in Iran. Arch Anim Breed 60: 183-189.

20. Soufy B, Mohammadabadi MR, Shojaeyan K, Baghizadeh A, Ferasaty S, et al. (2009) Evaluation of Myostatin gene polymorphism in Sanjabi sheep by PCR-RFLP method. Anim Sci Res 19: 81-89.

21. Shamsalddini S, Mohammadabadi MR, Esmailizadeh AK (2016) Polymorphism of the prolactin gene and its effect on fiber traits in goat. Genetika 52: 461-465.

22. Mousavizadeh A, Abadi MRM, Torabi A, Nassiry MR, Ghiasi H, et al. (2009) Genetic polymorphism at the growth hormone locus in Iranian Talli goats by polymerase chain reaction-single strand 
conformation polymorphism (PCR-SSCP). Iran J Biotechnol 7: 51-53.

23. Baghizadeh A, Bahaaddini M, Mohamadabadi MR, Askari N (2009) Allelic Variations in Exon 2 of Caprine MHC Class II DRB3 Gene in Raeini Cashmere Goat. AEJAES 6: 454-459.

24. Mohammadabadi MR, Nikbakhti M, Mirzaee HR, Shandi MA, Saghi DA, et al. (2010) Genetic variability in three native Iranian chicken populations of the Khorasan province based on microsatellite markers. Rus J Genet 46: 572-576.

25. Ruzina MN, Shtyfurko TA, Mohammadabadi MR, Gendzhieva OB, Tsedev T, et al. (2010) Polymorphism of the BoLA-DRB3 gene in the Mongolian, Kalmyk, and Yakut cattle breeds. Russ J Genet 46: 456-463.

26. Zhao LJ, Jiang H, Papasian CJ, Maulik D, Drees B, et al. (2008) Correlation of obesity and osteoporosis: effect of fat mass on the determination of osteoporosis. J Bone Miner Res 23: 17-29.

27. Kanis JA (1994) Assessment of fracture risk and its application to screening for postmenopausal osteoporosis: synopsis of a WHO report. WHO Study Group. Osteoporos Int 4: 368-381.

28. Gelayee DA (2017) Self-Medication Pattern among Social Science University Students in Northwest Ethiopia. Int J Pharm 2017: 5.

29. Faller AJ (1981) An Average Correlation Coefficient. J Appl Meteor 20: 203-205.

30. Smith DM, Nance WE, Kang KW, Christian JC, Johnston CC Jr (1973) Genetic factors in determining bone mass. J Clin Invest 52: 2800-2808.

31. Pocock NA, Eisman JA, Hopper JL, Yeates MG, Sambrook PN, et al. (1987) Genetic determinants of bone mass in adults. A twin study. J Clin Invest 80: 706-710.

32. Krall EA, Dawson-Hughes B (1993) Heritable and life-style determinants of bone mineral density. J Bone Miner Res 8: 1-9.

33. Keaveney M, Parker MG, Gannon F (1993) Identification of a functional role for the 3 ' region of the human oestrogen receptor gene. J Mol Endocrinol 10: 143-152.

34. Xia J, Scherer SW, Cohen PT, Majer M, Xi T, et al. (1998) common variant in PPP1R3 associated with insulin resistance and type 2 diabetes. Diabetes 47: 1519-1524.

35. Kenealy MR, Flouriot G, Sonntag-Buck V, Dandekar T, Brand H, et al. (2000) The 3'-untranslated region of the human estrogen receptor alpha gene mediates rapid messenger ribonucleic acid turnover. Endocrinology 141: 2805-2813.

36. Ioannidis JP, Stavrou I, Trikalinos TA, Zois C, Brandi ML, et al. (2002) ER-alpha Genetics Meta-Analysis. Association of polymorphisms of the estrogen receptor alpha gene with bone mineral density and fracture risk in women: a meta-analysis. J Bone Miner Res 17: 2048-2060.
37. Albagha $\mathrm{O}$, Pettersson $\mathrm{U}$, Stewart $\mathrm{A}$, McGuigan $\mathrm{F}$, MacDonald $\mathrm{H}$, et al. (2005) Association of oestrogen receptor a gene polymorphisms with postmenopausal bone loss, bone mass, and quantitative ultrasound properties of bone. J Med Genet 42: 240-246.

38. Lindsay R, Aitken J, Anderson L, Hart D, MacDonald E, et al. (1976) Long-term prevention of postmenopausal osteoporosis by oestrogen: evidence for an increased bone mass after delayed onset of oestrogen treatment. Lancet 307: 1038-1041.

39. Ettinger B, Genant HK, Cann CE (1985) Long-term estrogen replacement therapy prevents bone loss and fractures. Ann Intern Med 102: 319-324.

40. Riggs BL, Melton LJ 3rd (1986) Involutional osteoporosis. N Engl J Med 314: 1676-1686.

41. Felson DT, Zhang Y, Hannan MT, Kiel DP, Wilson PW, et al. (1993) The effect of postmenopausal estrogen therapy on bone density in elderly women. N Engl J Med 329: 1141-1146.

42. Korach KS (1994) Insights from the study of animals lacking functional estrogen receptor. Science (New York, NY) 266: 1524-1527.

43. Morishima A, Grumbach MM, Simpson ER, Fisher C, Qin K (1995) Aromatase deficiency in male and female siblings caused by a novel mutation and the physiological role of estrogens. J Clin Endocrinol Metab 80: 3689-3698.

44. Rochira V, Balestrieri A, Faustini-Fustini M, Carani C (2001) Role of estrogen on bone in the human male: insights from the natural models of congenital estrogen deficiency. Mol Cell Endocrinol 178: 215-220.

45. Gómez R, Magaña JJ, Cisneros B, Pérez-Salazar E, Faugeron S, et al. (2007) Association of the estrogen receptor alpha gene polymorphisms with osteoporosis in the Mexican population. Clin Genet 72: 574-581.

46. Wardlaw GM (1996) Putting body weight and osteoporosis into perspective. Am J Clin Nutr 63: 433S-436S.

47. Guney E, Kisakol G, Ozgen G, Yilmaz C, Yilmaz R, et al. (2003) Effect of weight loss on bone metabolism: comparison of vertical banded gastroplasty and medical intervention. Obes Surg 13: 383-388.

48. Radak TL (2004) Caloric restriction and calcium's effect on bone metabolism and body composition in overweight and obese premenopausal women. Nutr Rev 62: 468-481.

49. Zhao LJ, Liu YJ, Liu PY, Hamilton J, Recker RR, et al. (2007) Relationship of obesity with osteoporosis. J Clin Endocrinol Metab 92: 1640-1646. 